Communications in Physics, Vol. 24, No.3S1 (2014), pp. 13-21

DOI:10.15625/0868-3166/24/3S1/3267

\title{
ELECTRIC CHARGING AND COLLOID STABILITY OF FABRICATED NEEDLE-LIKE $\mathrm{TiO}_{2}$ NANOPARTICLES
}

\author{
KENTO UENO \\ Graduate School, University of Tsukuba, 1-1-1 Tennodai, Tsukuba, Ibaraki 305-8572, Japan \\ MOTOYOSHI KOBAYASHI AND YASUHISA ADACHI \\ Faculty of Life and Environmental Sciences, University of Tsukuba, \\ 1-1-1 Tennodai, Tsukuba, Ibaraki 305-8572, Japan \\ TAKASHI KOJIMA \\ Graduate School of Science and Technology, Chiba University, \\ 1-33 Yayoicho, Inage-ku, Chiba 263-8522, Japan \\ E-mail: kobayashi.moto.fp@u.tsukuba.ac.jp \\ Received 04 April 2014 \\ Accepted for publication 24 May 2014
}

\begin{abstract}
Charging and stability of needle-like $\mathrm{TiO}_{2}$ nanoparticles were studied. Measured isoelectric point (IEP) was $\mathrm{pH} \sim 4$ and lower than that of spherical ones $\mathrm{pH} \sim 6$. Heat treatment at $400^{\circ} \mathrm{C}$ changed the IEP from 4 to 6 . The shift is probably due to shape controller (ethylenediamine). The particles aggregate around IEP and thus are chargestabilized. Experimental hydrodynamic diameters of needle-like particles showed a reasonably good agreement with the theoretical diameter. That is, the particles can be dispersed to primary particles. $1 \mathrm{pK}$ Stern and standard electrokinetic models describe electrophoretic mobility of needle-like $\mathrm{TiO}_{2}$, indicating that double layer relaxation is significant for needle-like $\mathrm{TiO}_{2}$.
\end{abstract}

Keywords: electrophoretic mobility, isoelectric point, 1pK Stern model, double layer relaxation, aggregation, hydrodynamic diameter.

\section{INTRODUCTION}

The appearance of nanomaterial leads to significant changes in the world of science and engineering. Chemical and physical properties expected for nanomaterials are determined by their size, shape (morphology), composition, reactivity, and surface chemistry [1]. Titanium dioxide $\left(\mathrm{TiO}_{2}\right.$ : titania) is a naturally occurring mineral and has emerged as one of the most fascinating nanomaterials in modern era. $\mathrm{TiO}_{2}$ nanoparticles have been extensively used in industrial and environmental technology due to their various special characteristics (i.e. ultraviolet-absorption, redox reactivity, insulation, chemically-inert and stability) [2,3]. From these properties, they are applied as photocatalyst, coloring, and cosmetics, etc.

(C)2014 Vietnam Academy of Science and Technology 
In many cases, nanoparticles are dispersed in liquid medium and are provided as slurry in manufacturing. To control the properties of the slurry, it is important to characterize the aggregation, dispersion and charging behaviors of the titania nanoparticles. By contrast, for the wide range use of titania as a nanomaterial and its general versatility, their release into the environment and toxicity to human health are concerned [2,3]. Recent papers report that the positive electric surface charge and aggregation state of nanoparticles affect the growth of bacterial cells $[4,5]$. Therefore, to advance the technical use of titania nanoparticles and to assess the environmental risk, it is crucial to understand the $\mathrm{pH}$-dependent surface electric charging as well as aggregation-dispersion of titania nanoparticles.

Isoelectric point (IEP, $\mathrm{pH}$ at zero electrophoretic mobility) or point of zero charge (PZC, $\mathrm{pH}$ at zero surface charge) of $\mathrm{TiO}_{2}$ nanoparticles is one of the crucial parameters related to charging. Nevertheless, the values of titania are not yet definitive. While many researchers reported that IEP of $\mathrm{TiO}_{2}$ is around $\mathrm{pH} 6$, literature values of the $\mathrm{PZC}$ or IEP are in the range from $\mathrm{pH} 2$ to 8.4 [6]. This is attributed to the use of commercially available titania particles that may contain unknown chemical additives or impurities ( $\mathrm{Si}, \mathrm{P}$, surfactant, trace metal) and other crystalline composition [7]. Sugimoto and Zhou [8] concluded that the PZC of Ti(OH) 4 precipitate is 4.6 and anatase-type spherical titania particles have PZC of pH 6.0.

Recently, shape controlled needle-like anatase-type titania nanoparticles are well-studied, because of their characteristic chemical and physical properties $[9,10]$. Nevertheless, the effect of the shape controller on the surface charging and IEP of needle-like $\mathrm{TiO}_{2}$ nanoparticles has not yet been systematically studied. Also, standard 1pK Stern and electrokinetic models that describe charging properties of several colloidal particles have not been tested for the needle-like $\mathrm{TiO}_{2}$ nanoparticles. Furthermore, the experiment of colloid stability and theoretical analysis of hydrodynamic size of the needle-like $\mathrm{TiO}_{2}$ nanoparticles associated with their surface charging are scarce.

In this context, we synthesized anatase-type spherical and needle-like titania nanoparticles with non-impurities, better to say with known ingredients and additives, by hydrothermal treatment of titanium hydroxide gel $[8,9,11-14]$. Characterizing these non-impurity nanoparticles as a standard model particle will lead us to get the accurate data and the correct understanding of surface charging and dispersion properties of $\mathrm{TiO}_{2}$ needle-like nanoparticles. This paper discusses the results on the surface charge characteristics, aggregation and sedimentation, and hydrodynamic size of the needle-like $\mathrm{TiO}_{2}$ nanoparticles in aqueous solution.

\section{EXPERIMENTAL}

Both spherical and needle-like titania particles were synthesized according to the previous work reported by Kojima et al. [9]. That is, triethanolamine was added to titanium isopropoxide with molar ratio of [triethanolamine]:[titanium isopropoxide] $=2: 1$. Then, ethylenediamine and purified water was added to this mixture solution of triethanolamine and titanium isopropoxide. At this time, the concentrations of titanium isopropoxide and ethylenediamine were diluted to $0.25 \mathrm{M}$ and $0.2 \mathrm{M}$, respectively. Then, this precursor solution was put into a screw bottle and heat-treated at $100^{\circ} \mathrm{C}$ for $24 \mathrm{~h}$ for gelation. After this treatment, obtained gels were placed into a PTFE-lined autoclave and hydrothermally-treated at $140^{\circ} \mathrm{C}$ for $72 \mathrm{~h}$. The prepared particles were washed 5 times by centrifugation with purified water. Spherical titania particles were synthesized by almost the same way, however, without an addition of shape controller (ethylenediamine) that is needed to 
produce needle-like $\mathrm{TiO}_{2}$ particles. The crystalline structures of spherical and needle-like titania nanoparticles were identified by X-ray diffractometry (XRD; MacScience, M18X-HF-SRA) using $\mathrm{CuK} \alpha$ radiation. The morphology of the samples was observed by scanning electron microscope (SEM; JEOL, JSM-6330F).

Electrophoretic mobility (EPM) of $\mathrm{TiO}_{2}$ nanoparticles was obtained by Zetasizer NanoZS (Malvern). The instrument uses electrophoretic light scattering technique. The measurements of EPM were performed at three different $\mathrm{KCl}$ concentrations $\left(10^{-2} \mathrm{M}, 10^{-3} \mathrm{M}, 10^{-4} \mathrm{M}\right)$ as a function of $\mathrm{pH}$, which was adjusted by using $\mathrm{NaOH}$ and $\mathrm{HCl}$. The concentration of $\mathrm{TiO}_{2}$ suspension was $0.02 \mathrm{~g} / \mathrm{L}$. The used suspensions were sonicated before the measurement. The suspension $\mathrm{pH}$ was checked by using a combination electrode (6.0234.110, Metrohm).

Aggregation and sedimentation behavior of titania nanoparticles was studied at constant $\mathrm{KCl}$ concentrations $\left(10^{-4} \mathrm{M}\right)$ as a function of $\mathrm{pH}$. The particle concentration was $0.08 \mathrm{~g} / \mathrm{L}$. The $\mathrm{pH}$ was controlled by the addition of $\mathrm{NaOH}$ and $\mathrm{HCl}$. After the $0.08 \mathrm{~g} / \mathrm{L}$ titania suspensions were ultrasonicated to make them homogeneous, they were left unmoved for $24 \mathrm{~h}$. Aggregation-dispersion behavior of the suspension was judged by the naked eye observation; aggregated suspension shows clear supernatant and sediment. To quantify the degree of aggregation, $1 \mathrm{~mL}$ aliquots of the suspensions were taken from the supernatant without disturbing the sediments. The absorbance (ABS) of the supernatant was measured in a cell with an optical path length of $1 \mathrm{~cm}$ by using a spectrophotometer (Hitachi, U-1800) at the wave length of light of $600 \mathrm{~nm}$. The $\mathrm{pH}$ values of odd suspensions were measured by the combination electrode (6.0234.110, Metrohm). In addition, the average hydrodynamic diameter of needle-like titania particles $d_{H}$ was obtained by dynamic light scattering (DLS) method using the Zetasizer NanoZS as a function of $\mathrm{pH}$.

\section{THEORETICAL ANALYSES}

\section{III.1. Hydrodynamic size of rod shaped particles}

The theoretical hydrodynamic diameter of needle-like $\mathrm{TiO}_{2}$ was evaluated by the method described in the paper by Tirado et al. [15]. The shape of particles was assumed as a rod with a length $L$ and diameter $d$, for which the diffusion constant is given by

$$
\begin{gathered}
D=\frac{k_{B} T}{3 \pi \eta L}(\ln p+v) \\
v=0.312+0.565 / p-0.100 / p^{2}
\end{gathered}
$$

where $k_{B} T$ is the thermal energy, $\eta$ is the viscosity of medium, $p$ is the aspect ratio $p=L / d$.

The hydrodynamic diameter $\left(d_{h}\right)$ is obtained from the diffusion coefficient using the StokesEinstein equation:

$$
d_{h}=k_{B} T /(3 \pi \eta D) .
$$

The hydrodynamic diameter determined by dynamic light scattering (DLS) is usually the intensity-weighted average size $d_{h, a v}$. In a polydisperse system, $d_{h, a v}$ is given by [16]

$$
d_{h, a v}=\left\langle d_{h}^{6}\right\rangle /\left\langle d_{h}^{5}\right\rangle
$$

where $\langle\ldots\rangle$ means averaging. We calculate an average theoretical hydrodynamic size $d_{h, a v}$ by Eqs. (1)-(4) by assuming that $L$ and $d$ are comparable to the long axis length and short axis length of each needle-like particles measured from SEM pictures. And then, we compare $d_{h, a v}$ 
with $d_{H}$ from experiments using DLS. When these hydrodynamic diameters reasonably agree, we can judge the particles in a suspension are dispersed into primary particles. Such comparison has never been attempted for the needle-like $\mathrm{TiO}_{2}$.

\section{III.2. Model of charging behavior}

The charging behavior of metal oxides, including needle-like $\mathrm{TiO}_{2}$ used in this study, can be rationalized as surface complexation models like $1 \mathrm{p} K$ Stern model [17,18]. This $1 \mathrm{p} K$ Stern model assumes the protonation at the surface of metal oxides is a single reaction. In $\mathrm{TiO}_{2}$ case, the dissociation of proton at the surface can be shown as $\mathrm{TiOH}_{2}^{+1 / 2} \rightleftarrows \mathrm{TiOH}^{-1 / 2}+\mathrm{H}^{+}$with the acid dissociation constant $K$ given by

$$
K=\frac{\left[\mathrm{TiOH}^{-1 / 2}\right] 10^{-p H} \exp \left(-e \psi_{0} / k_{B} T\right)}{\left[\mathrm{TiOH}_{2}^{+1 / 2}\right]}
$$

where $\Psi_{0}$ is the surface potential, $e$ is elementary charge, square brackets denote surface concentrations of surface species.

The $1 \mathrm{p} K$ Stern model takes into account a formation of counterion pair at Stern plane. This reaction for $\mathrm{TiO}_{2}$ surface in $\mathrm{KCl}$ solution is given by $\mathrm{TiOH}_{2}^{+1 / 2} \cdot \mathrm{Cl}^{-} \rightleftarrows \mathrm{TiOH}_{2}^{+1 / 2}+\mathrm{Cl}^{-}$ andTiOH $^{-1 / 2} \cdot \mathrm{K}^{+} \rightleftarrows \mathrm{TiOH}^{-1 / 2}+\mathrm{K}^{+}$. The mass action law of each reaction is described by

$$
\begin{gathered}
K_{+}=\frac{\left[\mathrm{TiOH}^{-1 / 2}\right] a_{K} \exp \left(-e \Psi_{d} / k_{B} T\right)}{\left[\mathrm{TiOH}_{2}^{-1 / 2} \cdot K^{+}\right]} \\
K_{-}=\frac{\left[\mathrm{TiOH}^{+1 / 2}\right] a_{C l} \exp \left(e \Psi_{d} / k_{B} T\right)}{\left[\mathrm{TiOH}^{+1 / 2} \cdot C l^{-}\right]}
\end{gathered}
$$

where $\Psi_{d}$ is the potential at the Stern plane or diffuse layer potential, which is the potential at the origin of diffuse double layer. $a_{K}$ and $a_{C l}$ are activites of each ion in mole per volume.

The total number density of adsorption sites at the surface $\Gamma_{0}$ is described as

$$
\Gamma_{0}=\left\{\left[\mathrm{TiOH}_{2}^{+1 / 2}\right]+\left[\mathrm{TiOH}_{2}^{+1 / 2} \cdot \mathrm{Cl}^{-}\right]+\left[\mathrm{TiOH}^{-1 / 2}\right]+\left[\mathrm{TiOH}^{-1 / 2} \cdot \mathrm{K}^{+}\right]\right\} N_{A}
$$

where $N_{A}$ is the Avogadro number. The surface charge density $\sigma_{0}$ is thus written by

$$
\sigma_{0}=0.5 e N_{A}\left(\left[\mathrm{TiOH}_{2}^{+1 / 2}\right]+\left[\mathrm{TiOH}_{2}^{+1 / 2} \cdot \mathrm{Cl}^{-}\right]-\left[\mathrm{TiOH}^{-1 / 2}\right]-\left[\mathrm{TiOH}^{-1 / 2} \cdot \mathrm{K}^{+}\right]\right) \text {. }
$$

The Stern layer can be modeled by a parallel plate type condenser and is expressed by

$$
\sigma_{0}=C_{s}\left(\Psi_{0}-\Psi_{d}\right)
$$

where $C_{s}$ is the Stern layer capacitance. The Stern plane has the charge density and is given by

$$
\sigma_{s}=e N_{A}\left(\left[\mathrm{TiOH}^{-1 / 2} \cdot \mathrm{K}^{+}\right]-\left[\mathrm{TiOH}_{2}^{+1 / 2} \cdot \mathrm{Cl}^{-}\right]\right) .
$$

For the diffuse part of electric double layer, the relationship between charge density $\sigma_{d}$ and the diffuse layer potential $\Psi_{d}$ is described by the Gouy-Chapman theory in 1-1 electrolyte solution 
like $\mathrm{KCl}$ :

$$
\begin{gathered}
\sigma_{d}=-\left(2 \varepsilon_{r} \varepsilon_{0} \kappa k_{B} T / e\right) \sinh \left(e \Psi_{d} / 2 k_{B} T\right) . \\
\kappa^{-1}=\left(\varepsilon_{r} \varepsilon_{0} k_{B} T / 2 e^{2} N_{A} I\right)^{1 / 2}
\end{gathered}
$$

where $\kappa^{-1}$ is the Debye length and $\varepsilon_{r} \varepsilon_{0}$ is the total permittivity of water, $I$ is ionic strength. Electro-neutrality requires the following condition.

$$
\sigma_{d}=-\left(\sigma_{0}+\sigma_{s}\right)
$$

The set of nine non-linear simultaneous equations $(5-12,14)$ was solved numerically. The total number density of adsorption sites is $\Gamma_{0}=5 \mathrm{~nm}^{-2}$ as a literature-based value [18]. The parameters $\left(C_{s}, p K=-\log _{10} K, p K_{+}=-\log _{10} K_{+}, p K_{-}=-\log _{10} K_{-}\right)$can be tuned by comparing the calculated values with experimental data of surface charge density of $\mathrm{TiO}_{2}$ reported by van Riemsdijk et al. (rutile) [19] and Volkova et al.(anatase) [20].

Theoretical values of electrophoretic mobility (EPM) can be calculated by substituting zeta potential into appropriate theoretical equations. While there are several discussions on the position of slipping plane where zeta potential is defined [21,22], we assume that the zeta potential is identical to the diffuse layer potential (i.e. $\zeta=\Psi_{d}$ ) determined from $1 \mathrm{p} K$ model with the tuned parameters and $\mathrm{p} K=$ IEP. Two types of EPM theories were applied to convert zeta potential to EPM. One is the EPM theory for rod-shape particles without considering the effect of diffuse layer relaxation. According to Ohshima [23], the EPM $\mu_{m}$ of a rod with a radius $R=d / 2$ is given by

$$
\begin{aligned}
\mu_{m} & =\varepsilon_{r} \varepsilon_{0} \zeta[1+2 f(\kappa R)] / 3 \eta \\
f(\kappa R) & =\frac{1}{2}\left[1+\frac{1}{(1+(2.55 / \kappa R\{1+\exp (-\kappa R)\}))^{2}}\right] .
\end{aligned}
$$

To take into account the effect of diffuse layer relaxation reducing EPM, one needs numerical computation programs to solve electrokinetic problems. Unfortunately, however, such a program for rod-shape particles is not available. Therefore, in this study, we adopt a software program "cellmobility" that describes electrokinetic phenomena for spherical particles with the relaxation effect [24-27] using hydrodynamic size, zeta potential, and the scaled drag coefficient of ions. The software was provided to us by the authors of Refs. [24-26]. The EPM values calculated from these two methods are compared with experimentally obtained EPM of needle-like titania particles.

\section{RESULTS AND DISCUSSION}

Fig. 1 shows the SEM pictures of the synthesized titania. From the figure, we confirmed the formation of spherical and needle-like nanoparticles. XRD patterns (data not shown here) of spherical as well as needlelike titania particles demonstrated that these synthesized $\mathrm{TiO}_{2}$ particles were anatase type. The mean lengths of the needle-like titania along long and short axis esti-

Table 1. Size of needle-like $\mathrm{TiO}_{2}$ particles from SEM images

\begin{tabular}{|c|c|c|}
\hline & Unheated & Heated \\
\hline Long axis [nm] & $351 \pm 47$ & $300 \pm 45$ \\
\hline Short axis [nm] & $40 \pm 6$ & $37 \pm 7$ \\
\hline
\end{tabular}



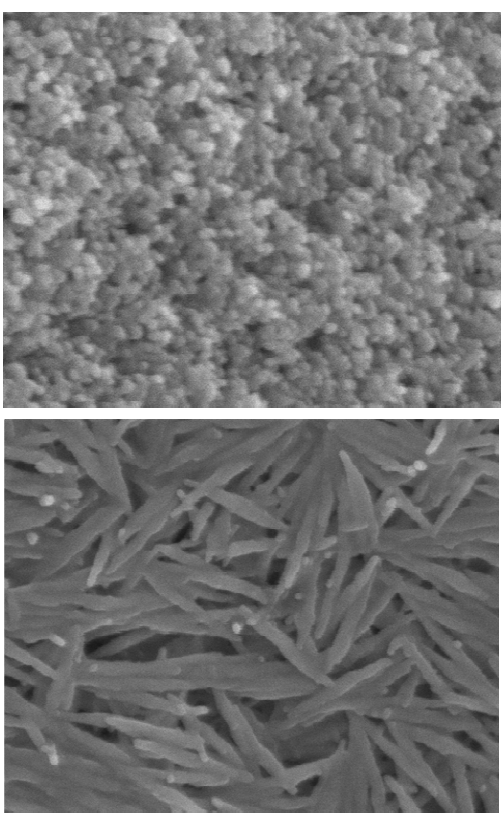

$-100 n m$

Fig. 1. SEM images of synthesized titania particles : top) without ethylenediamine (ED) and bottom) with ED
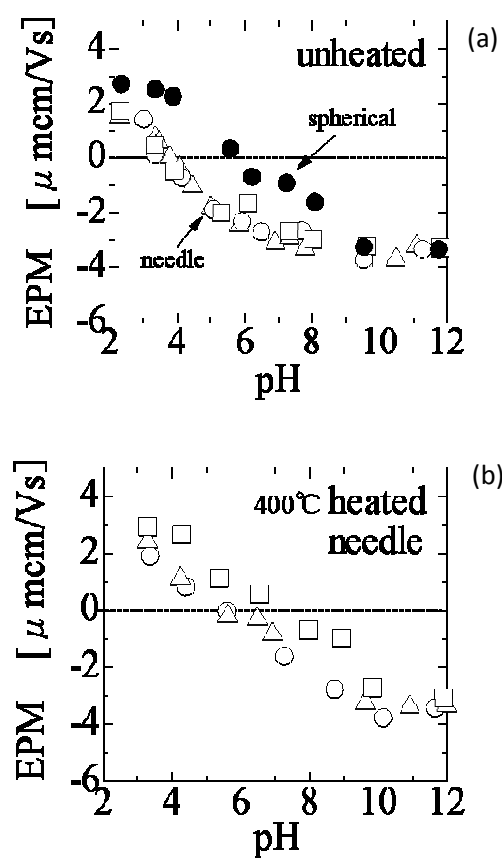

Fig. 2. Electrophoretic mobility (EPM) of titania as a function of $\mathrm{pH} \bullet$ spherical $\left(10^{-4} \mathrm{~mol} / \mathrm{L}\right)$, o needle-like $\left(10^{-4} \mathrm{~mol} / \mathrm{L}\right)$, $\triangle$ needle-like $\left(10^{-3} \mathrm{~mol} / \mathrm{L}\right), \square$ needle-like $\left(10^{-2} \mathrm{~mol} / \mathrm{L}\right)$

Table 2. Hydrodynamic diameter $d_{H}(\mathrm{~nm})$ of needle-like $\mathrm{TiO}_{2}$ particles obtained by dynamic light scattering

\begin{tabular}{|c|c|c|c|}
\hline \multicolumn{2}{|c|}{ Unheated } & \multicolumn{2}{c|}{ Heated } \\
\hline $\mathrm{pH}$ & $d_{H}$ & $\mathrm{pH}$ & $d_{H}$ \\
\hline 7.0 & 115 & 7.1 & 410 \\
\hline 8.0 & 116 & 7.8 & 163 \\
\hline 9.1 & 117 & 8.8 & 135 \\
\hline 9.9 & 118 & 10.1 & 118 \\
\hline
\end{tabular}

Measured EPM values of spherical and needle-like titania particles are plotted against $\mathrm{pH}$ for different ionic strength in Fig. 2(a). From the figure, we found that the IEP of spherical titania is around $\mathrm{pH} 6$, but needle-like titania particles have IEP around $\mathrm{pH} 4$. In the present method of synthesis, the only difference between spherical and needle-like particles is the existence of ethylenediamine added to make the needle-like particles. Therefore, we think that decreasing the IEP is due to the presence of ethylenediamine or its by-products. To prove this, needle-like titania particles were treated in TG-DTA (Rigaku, TG8120) to confirm the presence of ethylenediamine from the variation of the weight of needle-like titania particles. The TG-TDA analysis (data not shown here) showed a slight decreasing change around $400^{\circ} \mathrm{C}$. To remove ethylenediamine, we 
heated the needle-like $\mathrm{TiO}_{2}$ at $400{ }^{\circ} \mathrm{C}$. The SEM images of heated $\mathrm{TiO}_{2}$ (Fig. 3) demonstrated that the needle-shape remained after the heat treatment. The size of heated particles is also seen in Table 1. Comparing the sizes of heated and unheated particles, one can find that the heat treatment gives rise to the shrink of the particles. The EPM values of the heated needle-like titania are shown in Fig. 2(b). The figure indicates that the heat treatment shifts IEP from $\mathrm{pH} 4$ to $\mathrm{pH}$ 6, which is IEP for spherical titania particles. The shift of IEP by heating means that the lower IEP of original needle-like titania originates from the shape controller (ethylenediamine) which can be removed by heating at $400^{\circ} \mathrm{C}$. From these results, we found that needle-like $\mathrm{TiO}_{2}$ nanoparticles with usual IEP (pH 6) can be obtained by heating at $400{ }^{\circ} \mathrm{C}$.

Results of aggregation and sedimentation experiments are demonstrated in Fig. 4. In this figure, lower values of ABS (absorbance of supernatant) mean the formation of clearer supernatant induced by aggregation and subsequent sedimentation. From the figure, it is obviously seen that the unheated and heated needlelike $\mathrm{TiO}_{2}$ suspensions aggregate around $\mathrm{pH} 4$ and $\mathrm{pH} 6$, respectively. This result conforms to the EPM result. That is, the particles aggregate near IEP due to charge neutralization and disperse at $\mathrm{pH}$ being far from IEP by electrostatic repulsion. The DLS measurements provided the values of hydrodynamic diameters $d_{H}$ at different $\mathrm{pH}$ (Table 2). The values of $d_{H}$ of heated $\mathrm{TiO}_{2}$ are large around $\mathrm{pH} \sim 7$ ( $\sim \mathrm{IEP})$, indicating the formation of aggregates. On the contrary, $d_{H}$ at higher

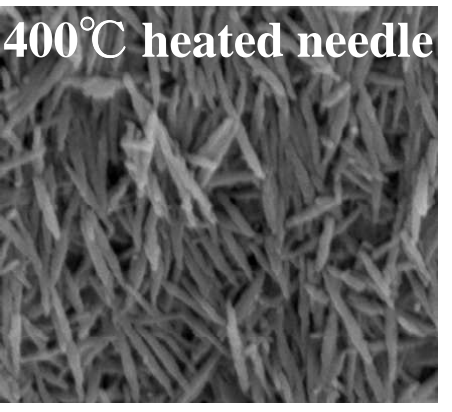

$-100 \mathrm{~nm}$

Fig. 3. SEM images of heat-treated needle-like titania nanoparticle
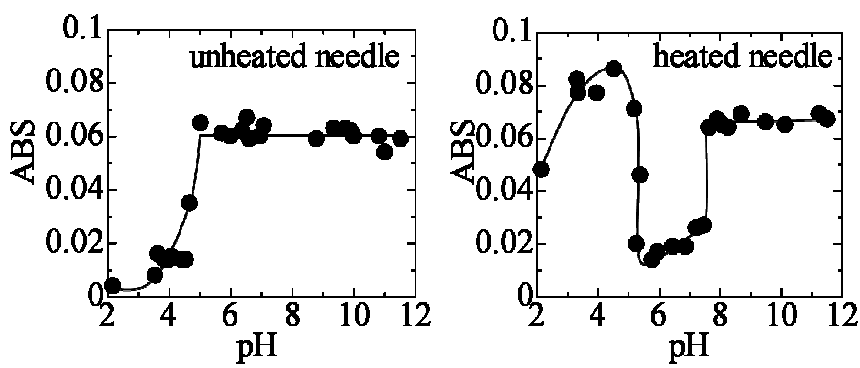

Fig. 4. Aggregation and sedimentation behavior of titania nanoparticles. Lower ABS (absorbance of upper part of suspension) means the occurrence of aggregation and sedimentation. $\mathrm{pH}$ is between the lengths of long axis and short axis. The calculated theoretical values of $d_{h, a v}$ from the length measurement of SEM were $147 \mathrm{~nm}$ and $132 \mathrm{~nm}$ for unheated and heated particles. While the theoretical $d_{h, a v}$ are 10-20\% larger than measured $d_{H}$, these diameters were reasonably close, and thus demonstrating that our needle-like titania can be dispersed to nearly the size of primary particles in aqueous solution by electrostatic repulsive force. The size difference is probably due to the shape difference of rod and spheroidal needle. 
Fig. 5 shows the comparison of the $1 \mathrm{p} K$ Stern model (lines) with experimental data (symbols) of surface charge density of $\mathrm{TiO}_{2}$. The experimental values of surface charge density were taken from the previously published papers from different groups $[19,20]$. By fitting the model calculation and experimental data, we found that the use of parameter values $C_{s}=1.2 \mathrm{C} / \mathrm{Vm}^{2}, \mathrm{pK}^{+,-}=$ $-1.02, \mathrm{p} K=\mathrm{PZC}=6$ achieves a good agreement between model and experiment. By using the same parameters and setting $\mathrm{p} K=$ IEP ( 4 or 6 ), we calculated EPM of needle-like $\mathrm{TiO}_{2}$ as shown in Fig. 6, in which symbols are the experimental data, the broken lines are calculation by eq. (15), and the solid lines are drawn by using the "cellmobility" program taking account of the relaxation effect (RE) of double layer with hydrodynamic size $d_{H}$. Fig. 6 demonstrates that the EPM model without RE overestimates the magnitude of EPM. On one hand, the EPM evaluated with $1 \mathrm{p} K$ Stern and electrokinetic models including RE reasonably describe experimental EPM of unheated and heated titania particles. This result suggests that the relaxation effect (RE) is significant and the $1 \mathrm{pK}$ Stern and electrokinetic models including RE is successful for the prediction of EPM of needle-like $\mathrm{TiO}_{2}$ by using the assumption $\zeta=\Psi_{d}$ and hydrodynamic size. Also the difference of the parameters between unheated and heated tiatania particle is only $\mathrm{p} K$ given from the experimental value of IEP. This implies that the shape controller (ethylenediamine) shifts $\mathrm{p} K$ and thus IEP.

\section{CONCLUSIONS}

To clarify the electrophoretic mobility (EPM) and isoelectric point (IEP) as well as dispersionaggregation behaviors of needle-like titania nanoparticles under the same condition, we synthesized spherical and needle-like titania particles with known ingredients and additives. We found that the needle-like titania particles with shape controller, ethylenediamine, show lower IEP compared to spherical titania particles. After the thermal treatment at $400{ }^{\circ} \mathrm{C}$, the IEP of needle-like 
titania particles shifted from $\mathrm{pH} 4$ to $\mathrm{pH}$ 6. This result demonstrates that a small amount of organic substance added to control the shape affects the value of EPM and IEP. From the comparison of theoretical and experimental hydrodynamic diameters in dispersed state, needle-like titania nanoparticles can be dispersed to primary particles in aqueous solution. Also the surface charge density was described by the $1 \mathrm{p} K$ Stern model with the same parameters regardless of the crystalline structure. The theoretical EPM showed a good agreement with experimental EPM by taking account of the relaxation effect of electric double layer.

\section{ACKNOWLEDGMENTS}

This study was financially supported by the MEXT KAKENHI $(23688027,22248025)$

\section{REFERENCES}

[1] H. A. Godwin, K. Chopra, K. A. Bradley, Y. Cohen, B. H. Harthorn, E. M. V. Hoek, P. Holden, A. A. Keller, H. S. Lenihan, R. M. Nisbet, and A. E. Nel, Environ. Sci. Technol. 43 (2009) 6453.

[2] J. Nakanishi, Risk Assessment of Manufactured Nanomaterials: "Approaches" - Overview of Approaches and Results, Final Report, NEDO project "Research and Development of Nanoparticle Characterization Methods", 2011.

[3] J. Nakanishi, Risk Assessment of Manufactured Nanomaterials: Titanium Dioxide (TiO 2 ), Final Report, M. Gamo, NEDO project "Research and Development of Nanoparticle Characterization Methods", 2011.

[4] A. Miyamoto, H. Tokumoto, Y. Konishi, and T. Nomura, J. Soc. Powder Technol. Japan 49 (2012) 362, in Japanese with English abstract.

[5] C. Pagnout, S. Jomini, M. Dadhwal, C. Caillet, F. Thomas, and P. Bauda, Colloids Surf. B, 92 (2012) 315.

[6] M. Kosmulski, J. Colloid Interface Sci. 353 (2011) 1.

[7] X. Liu, G. Chen, and C. Su, J. Colloid Interface Sci. 363 (2011) 84.

[8] T. Sugimoto, X. Zhou, J. Colloid Interface Sci. 252 (2002) 347.

[9] T. Kojima, R. Suzuki, N. Uekawa, and K. Kakegawa, J. Ceram. Soc. Japan, 115 (2007) 160.

[10] L. Ge, M. Xu, H. Fang, and M. Sun, Appl. Surf. Sci. 253 (2006) 720.

[11] T. Sugimoto, K. Okada, H. Itoh, J. Colloid Interface Sci. 193 (1997) 140.

[12] T. Sugimoto, X. Zhou, A. Muramatsu, J. Colloid Interface Sci. 252 (2002) 339.

[13] T. Sugimoto, X. Zhou, A. Muramatsu, J. Colloid Interface Sci. 259 (2003) 43.

[14] T. Sugimoto, X.Zhou, A. Muramatsu, J. Colloid Interface Sci., 259 (2003) 53.

[15] M. M. Tirado, C. L. Martinez, and J. C. De la Torre, J. Chem. Phys. 81 (1984) 2047.

[16] M. Kobayashi, F. Juillerat, P. Galletto, P. Bowen, and M. Borkovec, Langmuir 21 (2005) 5761.

[17] M. Schudel, S. H. Behrens, H. Holthoff, R. Kretzschmar, and M. Borkovec, J.Colloid Interface Sci. 196 (1997) 241.

[18] T. Hiemstra, J. C. M. de Wit, and W. H. van Riemsdijk, J. Colloid Interface Sci. 133 (1989) 105.

[19] W.H. van Riemsdijk, G. H. Bolt, L. K. Koopal, and J. Blaakmeer, J. Colloid Interface Sci. 109 (1986) 219.

[20] A.V. Volkova, L. E. Ermakova, N. F. Bogdanova, E. A. Tarabukina, and M. P. Sidorova, Colloid J. 72 (2010) 743.

[21] M. Kobayashi, Colloid Polym. Sci. 286 (2008) 935.

[22] T. D. Pham, M. Kobayashi, and Y. Adachi, Colloids Surf. A 436 (2013) 148.

[23] H. Ohshima, "Biophysical Chemistry of Biointerfaces", Wiley, New York, 2010.

[24] S. Ahualli, A. V. Delgado, S. J. Miklavcic, and L. R. White, Langmuir 22 (2006) 7041.

[25] S. Ahualli, A. V. Delgado, S. J. Miklavcic, and L.R. White, J. Colloid Interface Sci. 309 (2007) 342.

[26] B. H. Bradshaw-Hajek, S. J. Miklavcic, and L. R. White, Langmuir 25 (2009) 1961.

[27] M. Kobayashi, and A. Sasaki, Colloids Surf. A 440 (2014) 74. 